\title{
A Study on the Effect of Wire Composition on Welding with Gap and Offset in Cold Metal Transfer (CMT) GMAW
}

\author{
Md. R. U. Ahsan*,**, Taehoon Kim***, Duck bong Kim****, Changwook Ji*****, \\ and Yeong-Do Park**, \\ *Department of Mechanical Engineering, Tennessee Technological University, Cookeville, TN 38505, \\ United States of America \\ **Department of Advanced Materials Engineering, Dong-Eui University, Busan, 47340, Korea \\ ***R\&D Center, Kiswel Co. Ltd, Changwon, 704, Korea \\ ****Department of Manufacturing Engineering and Technology, Tennessee Technological University, \\ Cookeville, TN 38505, United States of America \\ *****Advanced Forming Process R\&D Group, Korea Institute of Industrial Technology, Ulsan, 44413, Korea \\ †Corresponding author : ypark@deu.ac.kr \\ (Received August 31, 2018 ; Revised October 1, 2018 ; Accepted October 11, 2018)
}

\begin{abstract}
In this paper, weldability of cold metal transfer (CMT) gas metal arc welding is studied for welding conditions with gap and offset for two different wire composition and strength. The two wires used have different surface tensions and viscosities due to the presence of differing amounts of sulfur and titanium, respectively. The difference in strength is induced mechanically during the wire drawing process. Surface tension and viscosity directly result in the wettability of molten metal, which in turn affects the gap bridging and weldability with offset. Experiments suggest that high viscosity and surface tension result in weld bead with higher elevation and a better gap-bridging ability. However, low viscosity and surface tension result in better wettability, which leads to better weldability with a higher offset. The understanding derived from this research can facilitate the development of welding consumables suitable for welding conditions with various offset and gaps.
\end{abstract}

Key Words : Cold metal transfer (CMT), Gas metal arc welding (GMAW), Viscosity, Surface tension, Gap

\section{Introduction}

To comply with the emission regulations, the automotive industry is beginning to use thinner sheets of metals made from higher strength materials ${ }^{1)}$. Gas metal arc welding (GMAW) is the most common method for welding chassis components in the automotive industry $^{2)}$. Chassis components vary in geometry and often have a gap ${ }^{3)}$. The sudden variation in geometry may often abruptly change the teaching position offsetting the welding torch from the intended location. Also, sudden gaps may appear and parts may be deformed plastically during welding due to poor clamping ${ }^{4)}$. To cover such gaps and offset, a high amount of deposition may be required ${ }^{5)}$. However, the deposition during welding is directly related to the heat input ${ }^{6}$. For high deposition rates, a high heat input is required ${ }^{2}$. Additionally, a welding configuration with offset or gap has a poor conduction heat transfer, as the sheet placed with offset or gap cannot conduct the equal amount of heat. Hence, chances of burn through are higher.

Cold metal transfer (CMT) is a recently developed automated GMAW process that uses a modified short-circuit method $^{2)}$. In the CMT process, the material deposition is mechanically assisted by retracting the wire. This eliminates the need for current for material deposition. This controlled method of material deposition produces a higher melting co-efficient than conventional welding processes. The ability to produce higher deposition with low heat input makes CMT a suitable process to weld thinner sheets. The inherent property of CMT can also 
facilitate the welding of joints with offset or gap.

Gap bridging and welding with an offset are also dependent on the physical properties of the weld metal. Viscosity and surface tension are among those physical properties and affect the fluidity of molten metal ${ }^{7)}$. A less viscous molten metal has higher wettability and can, hence, cover a larger area. Presence of some elements like titanium in steel can significantly change the viscosity and, hence, the wettability ${ }^{8)}$. Conversely, surface tension significantly contributes to the shape of the weld deposition $^{9-11)}$. In general, adding alloying elements lowers the surface tension ${ }^{9,11-14)}$. Addition of 0.1 $\mathrm{wt} \%$ of sulfur may reduce the surface tension of molten iron by about $30 \%{ }^{12)}$. With low surface tension, weld metal can flow more easily, resulting in a wider weld bead with a lower bead elevation.

A narrow, high weld bead may facilitaate welding with larger gap and little to no offset; hence, a high viscosity and convergent surface-tension-driven flow may be desired. However, while there is a large offset, a higher wettability is desired. Low viscosity and a divergent weld pool flow may facilitate such cases.

Previous researches have been conducted on GMA welding of the open gap in pipelines ${ }^{13)}$ and improvement of gap bridging ability in $\mathrm{CO}_{2}$ Laser-GMA hybrid welding ${ }^{14)}$. However, none of the previous works consider the effect of the weld pool flow and bead shape on the gap bridgeability and offset positions. In this work, two ER-70 grade welding wires are used with differing amounts of sulfur and titanium as these elements can change the surface-tension-driven flow and viscosity, respectively. Through a wide range of repeated experiments, the effect of welding wire composition on gap bridging and welding with offset has been studied. Additionally, the effect of wire strength is also considered. The difference in wire strength in this study is due to the different amount of work hardening during the wire drawing process. The outcome of this research can be used to develop wires for automotive applications along with improving the welding consumable manufacturing process.

\section{Experimental Methods}

For this study, the welds were made on a hot-rolled Galvannealed steel plate of thickness $3.2 \mathrm{~mm}$ and strength $440 \mathrm{MPa}$. The sheet was welded with $1.2 \mathrm{~mm}$ diameter

Table 1 Chemical composition of welding wires

\begin{tabular}{|c|c|c|c|c|c|c|c|c|}
\hline $\begin{array}{c}\text { Wire } \\
\text { Name }\end{array}$ & $\mathrm{C}$ & $\mathrm{Si}$ & $\mathrm{Mn}$ & $\mathrm{P}$ & $\mathrm{S}$ & $\mathrm{Cu}$ & $\mathrm{Al}$ & $\mathrm{Ti}$ \\
\hline Wire 1 & 0.067 & 0.650 & 1.169 & 0.013 & 0.013 & 0.011 & 0.001 & 0.001 \\
\hline Wire 2 & 0.065 & 0.631 & 1.192 & 0.010 & 0.004 & 0.014 & 0.004 & 0.100 \\
\hline
\end{tabular}

ER-70S wires. The composition of the wires is listed in Table 1. Each wire used has a high strength type and a low strength type. This difference in strength is due to the wire drawing process. The steels were welded in a single-lap joint configuration using a Fronius Trans Puls Synergic $^{\circledR} 3200$ machine and Yaskawa Motoman ${ }^{\circledR}$ robot with an argon- $\mathrm{CO}_{2}$ mixture (Ar: $\left.\mathrm{CO}_{2}=9: 1\right)$ as the shielding gas. A constant welding current of 200 Amp and welding speed of $80 \mathrm{cpm}$ were used throughout the study. The contact tip to workpiece distance (CTWD) was maintained at $15 \mathrm{~mm}$.

The sheets were welded with $0,1.0,1.5$ and $2.0 \mathrm{~mm}$ gaps. An offset range of $-33^{`} 3 \mathrm{~mm}$ was used. Offset value zero corresponds to the root of the lap joint configuration. The negative and positive directions are presented in the schematic in Fig. 1.

For the acceptance and rejection of a welding position, a criterion was set based on the measurement of the bead cross-section. For CMT GMAW with zero gaps, a penetration depth of $10 \%$ of base metal thickness on the lower plate is found to be adequate ${ }^{2)}$. For the given welding condition, the penetration depth (on the bottom plate) was found equal or higher than the $10 \%$ of the base metal thickness $(0.32 \mathrm{~mm})$ regardless of the offset position and gap. Hence, the acceptance criterion is set based on the fusion with the upper plate. The acceptance and rejection criteria are presented schematically in Fig. 2. To be accepted, the fusion zone at the upper plate produced by a welding condition shall reach up to the half of the thickness. To put it otherwise, when measured from the edge of the upper plate, the maximum distance to the fusion zone which can be accepted is $1.6 \mathrm{~mm}$ (half of the sheet thickness $3.2 \mathrm{~mm}$ ).

For the measurement of the cross section, the samples were cut, mounted and polished following metallographic procedures. The polished samples were etched with $2 \%$ picral. A Leica e $24 \mathrm{z}$ microscope was used to observe the samples at $10 x$ magnification. The meas-

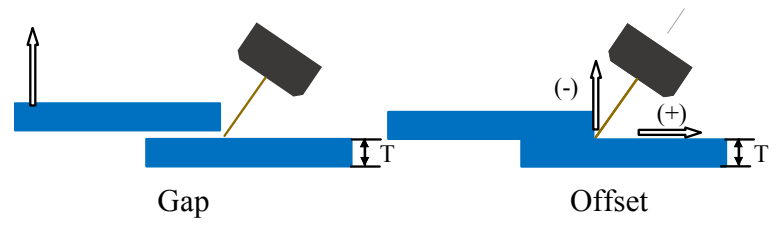

Fig. 1 Schematic representation of welding coditions

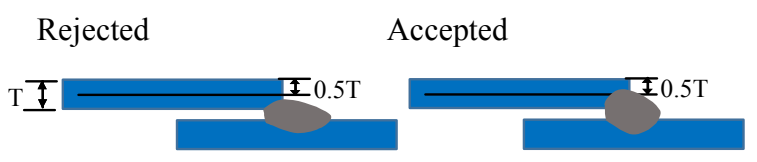

Fig. 2 Schematic representation of the acceptance criteria 
urements on the weld bead cross section were carried out using Image-Pro Plus ${ }^{\circledR}$ software.

\section{Results and Discussion:}

The welding in the bead on plate condition is first used to study the effect of wire composition on the welds. The results from the bead on plate (BOP) experiments are presented in Fig. 3. The cross sections show that the weld bead with wire 1 is wide whereas the weld bead with wire 2 is narrow and high. Bead cross section measurement showed that the weld bead with wire 1 had a width of $7.5 \mathrm{~mm}$. Whereas, the bead width of wire 2 weldment was $6.10 \mathrm{~mm}$. This phenomenon is attributed to the difference in viscosity and surface tension of the molten metal due to the compositional differences of the wires. Wire 1 contains high sulfur and low titanium with a low viscosity and a lower surface tension. As a result, it can easily spread out and create a wider weld pool. A similar result has been observed by Heiple et al. in their works on GTAW ${ }^{12,15,16)}$.

Later, experiments are carried out using all four wires with different gaps $(0,1.0,1.5$ and $2.0 \mathrm{~mm})$. Again, for each gap, seven offset positions are used, ranging from -3 to $+3 \mathrm{~mm}$ with 1 increment. The interpretation of negative and positive signs is presented in the schematic in Fig. 1. The cross sections are presented in Fig. 4. It can be noted that some bead cross sections contain void. This is attributed to the porosity formation during zinc evaporation. This issue has been addressed in the authors' previous work ${ }^{11,17)}$. The bead cross sections are measured and evaluated according to the acceptance criteria set in Fig. 2. In Fig. 4, the cross sections with a green background are acceptable according to the acceptance criteria whereas those with red backgrounds are rejected. The cross-marked conditions did not produce any joining between the two sheets. Comparison between the bead cross-section data shows that for the same composition of wire, the weldable range remains same regardless of the wire strength. However, for wire with different composition, the weldable range show some difference. In order to differentiate between the weldable range, the results from the weld bead cross-
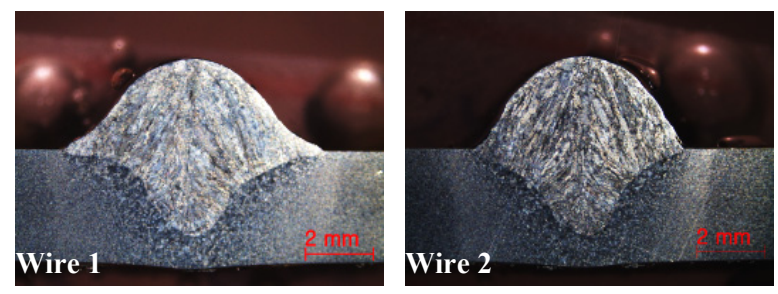

Fig. 3 Cross sections of weldbead in the bead on plate (BOP) welding condition section analysis were plotted to map the weldable area and presented in Fig. 5. The mapping shows that wire 2 has one more weldable condition (at offset -2) compared to wire 1 at the $2.0 \mathrm{~mm}$ gap. However, wire 1 has one more weldable condition at $1 \mathrm{~mm}$ gap (2 mm offset) than wire 2 . This difference is attributed to the difference in viscosity and surface tension. As stated earlier, wire 1 has a low viscosity and surface tension compared to wire 2 due to low titanium and high sulfur content. Hence, wire 2 produces a narrow, but higher, weld bead. The height of the weld bead allows for fusion with a top sheet at a higher gap. As a result, for the larger gap $(2.0 \mathrm{~mm})$, wire 2 is more effective than wire 1. However, welding with offset at the positive direction or away from the root requires more fluidity (less viscosity and surface tension) of the molten metal. Due to the composition of wire 1 , it has lower viscosity and surface tension. As a result, it is able to join with a narrow gap and larger offset.

The geometry of the bead cross section has also been analyzed for leg length and penetration depth in this work. These analyses are presented in Fig. 6 and 7 along with a schematic reorientation of measurement parameters in the bead cross-section. Fig. 6 show the change in leg length with different offset position at different gaps for all four wires. The general trend with the offset position is as the offset value increases, the leg length also increases regardless of the gap, wire composition or wire strength. As the offset increases or wire tip is moved away from the root, the molten metal gets more space to spread out in both directions. Additionally, with higher offset, the molten metal requires more time to reach the upper sheet. This allows the molten metal to cool down. As a result, the upper sheet receives a lesser amount of heat. Hence, molten metal cools down slowly. As the fluidity is higher at high temperature, slow cooling of molten metal results in higher fluidity for a longer period of time. This, coupled with more space to spread out, allows for a larger leg length with increasing offset. While the wire is offset at the negative direction, the higher is the teaching position, the less is the leg length. Offsetting the wire in the negative direction allows the top sheet to receive more heat. As a result, when the molten metal reaches the bottom sheet, it is colder compared to the case with a positive offset value. Hence, it lacks the fluidity required to spread out. Additionally, the molten metal solidifies rapidly allowing a smaller time frame to spread out.

At the same offset position, the leg length is usually higher with a gap for the positive values of offset position, compared to the welding condition with zero gaps. With gap, usually, the top sheet gets a lower amount of heat, slowing down the cooling. Additionally, the mol- 

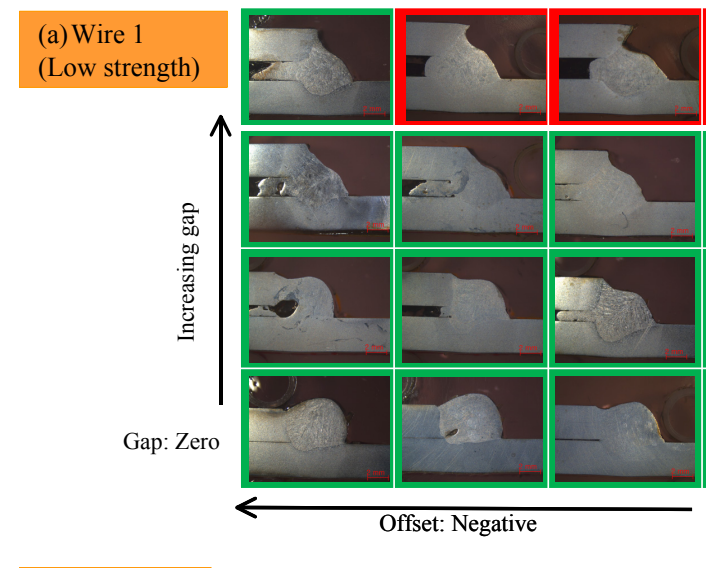

(b) Wire 1
(High strength)

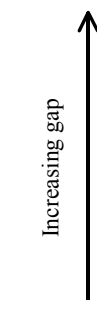

Gap: Zero
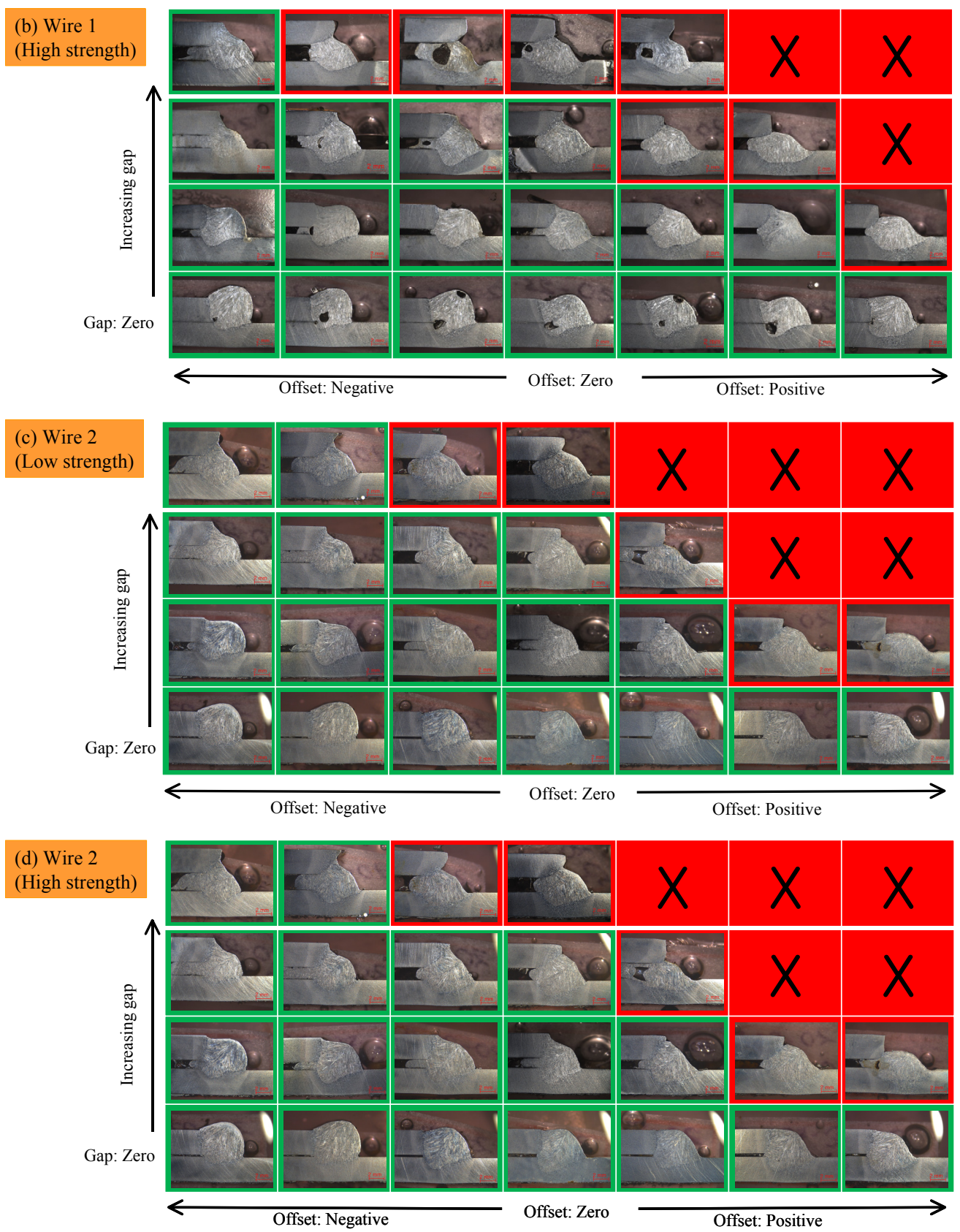

Fig. 4 Bead cross sections and acceptance/ rejection of the welding condition for (a) wire 1 ((Low strength), (b) wire 2 ((Low strength), (c) wire 1 ((High strength) and (d) wire 2 ((High strength). Greens are the conditions that are accepted and reds are the rejected ones 
(a) Wire 1

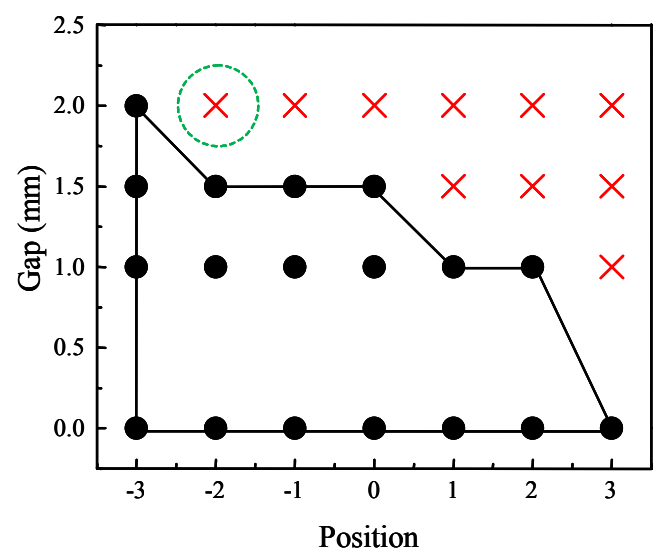

(b) Wire 2

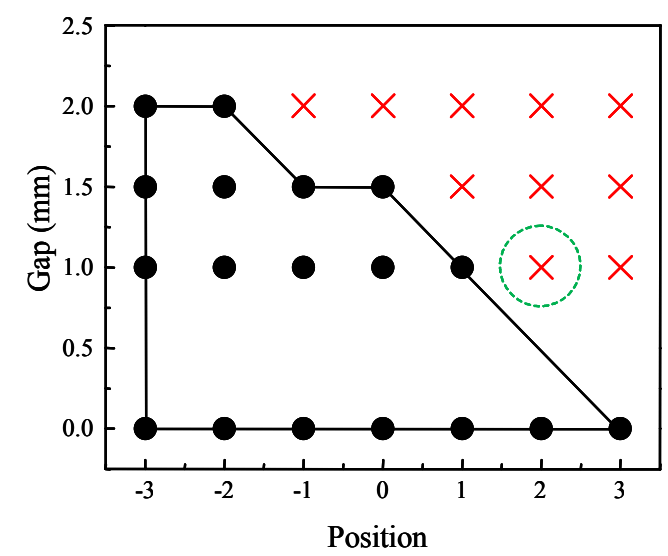

Fig. 5 Mapping of suitable welding condition based on acceptance criteria for (a) wire 1 and (b) wire 2
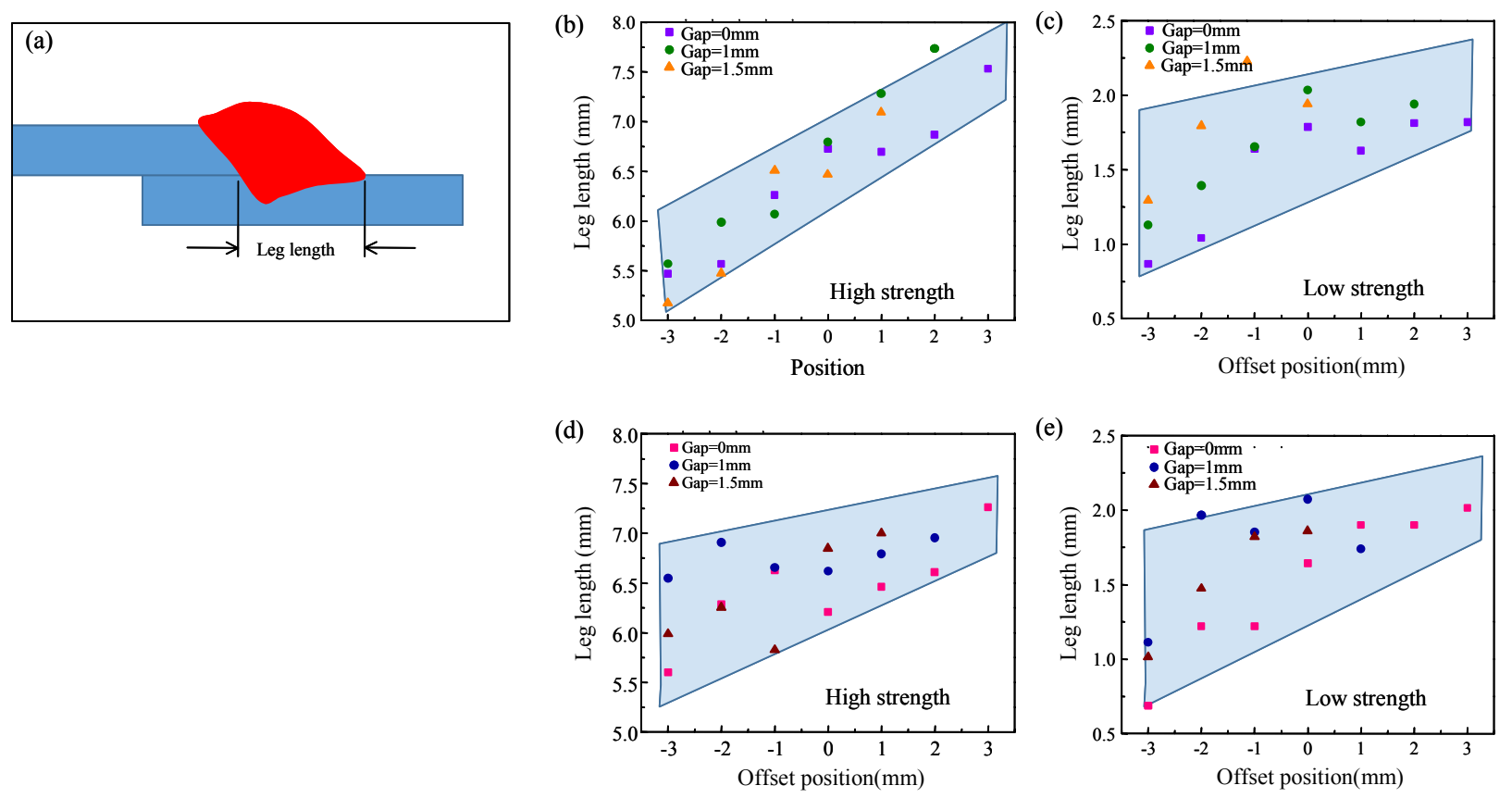

Fig. 6 (a) Schematic representation of measurement parameters on bead cross-section. Leg length as a function of offset position at different gaps for wire 1 (b) High strength (c) Low strength and wire 2 (d) High strength (e) Low strength

ten metal can spread inside the gap. Hence, at the same positive offset value, the leg length also increases with the presence of the gap. However, at the negative offset values, the leg length sometimes decreases with higher gaps. This may be attributed to the longer travel distance for the molten metal to reach the lower sheet. Due to the longer travel distance, the molten metal may have cooled down a little affecting the fluidity and shortening the leg length.

Although the leg length shows an increasing trend with increasing offset and gap for both wires, for wire 1 , the trend is more prominent, especially with higher gaps. This is due to the low viscosity and surface tension in wire 1 . As it has higher fluidity, it can spread out more easily, contributing to the larger leg length. The wire strength does not affect the trend. However, with higher strength wire, the data is spread over a narrower range. The possible reason could be the reduction in wire deflection with increasing strength. The lower deflection in wire may have allowed a more precise material deposition. As a result, a less scattered data is obtained.

The penetration-depth measurement data for the four different wires are presented in Fig. 7. The penetration depth is measured only at the lower sheet. With the 

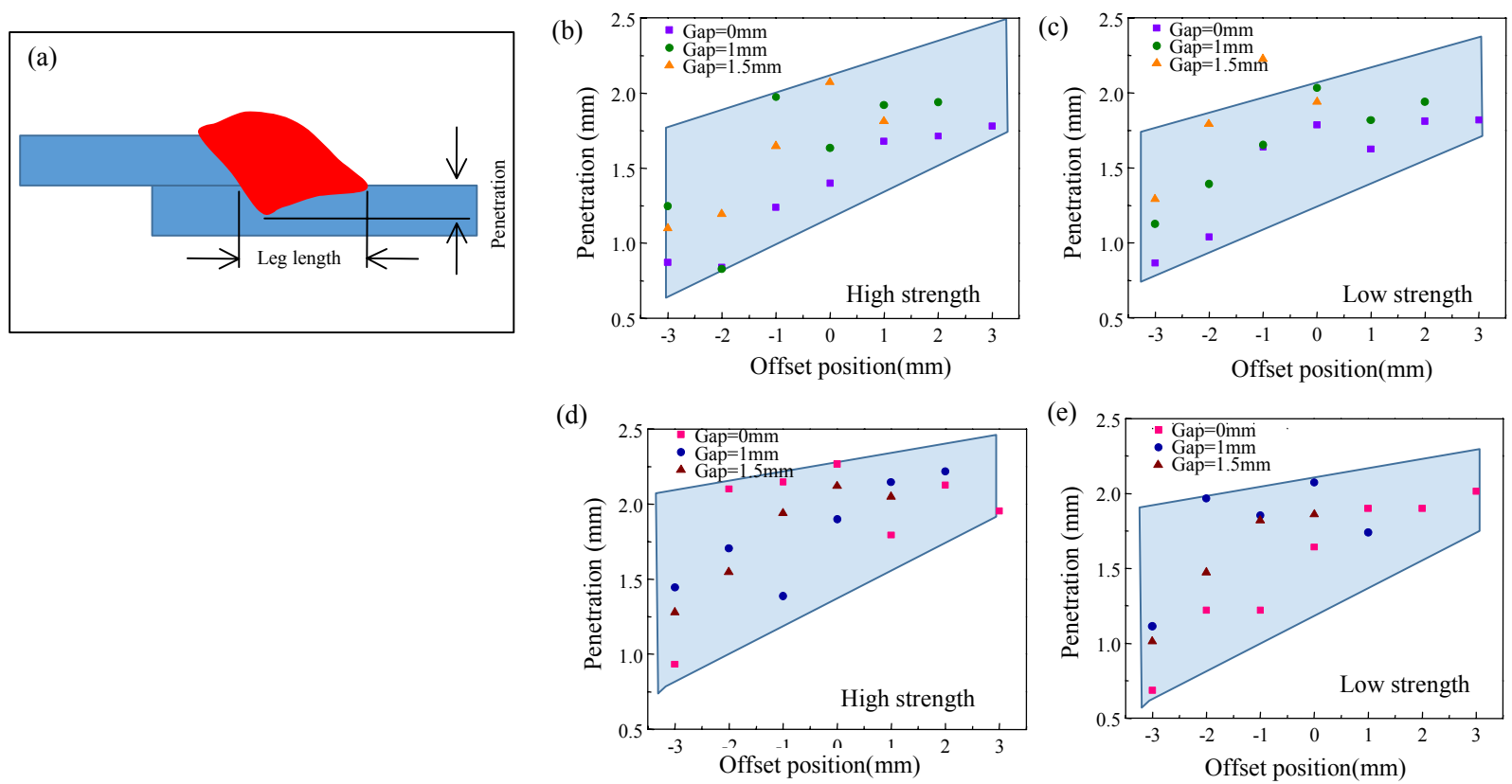

Fig 7 (a) Schematic representation of measurement parameters on bead cross-section. Penetration Depth as a function of offset position at different gaps for wire 1 (b) High strength (c) Low strength and wire 2 (d) High strength (e) Low strength

presence of either gap or offset, the lower sheet receives more heat. As a result, the penetration depth increases with increasing offset and the presence of the gap. For both wire compositions, the high and low strength variants give depth of penetrations at different offsets and gaps as shown on the graphs. Wire composition also seems not to have a significant effect on the depth of penetration in all welding conditions except for the ones with negative offset values. The low viscosity and surface tension wire (wire 1) seem to have a little more depth of penetration compared to the wire 2 at negative offset values. At negative offset values, the distance of material deposition location increases from the bottom plate. Hence, it takes longer for the molten metal to reach the bottom plate. As a result, in general, the penetration depth is lower for both wires than the zero or positive offset values. However, the low viscosity and surface tension of wire 1 may have allowed it to flow a little faster. Hence, the molten metal reached the lower sheet at a little high temperature and produced a little higher depth of penetration at negative offset values.

Wire with low surface tension and viscosity is suitable for welding with a larger offset in the direction away from the root of the weld joint. It also produces a higher depth of penetration with negative offset values. However, while the gap is wider, low viscosity and surface tension wire have a poor gap bridgeability. On the other hand, for bridging the larger gap, high surface tension wire is more suitable. Due to the lack of fluidity in the high viscosity and surface tension wire, it performs poorly when it is offset away from the root.

\section{Conclusion}

This paper discloses the effect of wire composition and wire strength on welding with a gap and offset. The study shows that mechanically induced wire strength does not affect the leg length, penetration depth or weldable zone significantly. However, wire composition can affect the weldability with a gap and offset significantly. Alloying elements like sulfur and titanium affect the physical properties like surface tension and viscosity of molten metal, respectively. Wire with high sulfur and low titanium has a low surface tension and viscosity, which results in a better fluidity. Hence, it can cover a large area and is suitable for welding with a larger offset. However, due to low surface tension, the bead elevation is often low. Hence, it will have a poorer performance with a larger gap. The wire with low sulfur and high titanium has high viscosity and surface tension, hence, a narrow and high bead. This makes it suitable for joining with a larger gap. However, it may not be suitable for welding with large offset due to low fluidity. The difference in surface tension and viscosity has a significant effect on leg length. However, their effect on the penetration depth is not significant.

\section{Acknowledgement}

This work was supported by Dong-Eui University Grant. (201802800001) 
ORCID: Md. R. U. Ahsan: http://orcid.org/0000-0002-2654-7974 ORCID: Taehoon Kim: http://orcid.org/0000-0002-8714-292X

ORCID: Duck bong Kim: http://orcid.org/0000-0003-4685-774X ORCID:Changwook Ji: https://orcid.org/0000-0002-5158-5243 ORCID:Yeong-Do Park: https://orcid.org/0000-0002-0165-4749

\section{References}

1. H.T. Zhang, J.C. Feng, P. He, B.B. Zhang, J.M. Chen, L. Wang, The arc characteristics and metal transfer behaviour of cold metal transfer and its use in joining aluminium to zinc-coated steel, Mater. Sci. Eng. A, 499 (2009), 111-113 https://doi.org/10.1016/j.msea.2007.11.124

2. Md. R. U. Ahsan, Y. R. Kim, R. Ashiri, Y. J. Cho, C. Jeong, Y. D. Park, Cold Metal Transfer ( CMT ) GMAW of Zinc - Coated Steel, Weld. J, 95 (2016), 120-132

3. F. Möller, H. Kügler, S. Kötschau, A. Geier, S.F. Goecke, Gap bridging ability in laser GMA hybrid welding of thin 22MnB5 sheets, Phys. Procedia, 56 (2014), 620- 629 https://doi.org/10.1016/j.phpro.2014.08.052

4. W.J. So, M.J. Kang, D.C. Kim, Weldability of pulse GMAW joints of $780 \mathrm{MPa}$ dual-phase steel, Achieves of Materials Science and Engineering, 41 (2010), 53-60

5. J.D. Van de Ven, A.G. Erdman, Bridging Gaps in Laser Transmission Welding of Thermoplastics, J. Manuf. Sci. Eng. 129 (2007), 1011 https://doi.org/10.1115/1.2769731

6. C.G. Pickin, K. Young, Evaluation of cold metal transfer (CMT) process for welding aluminium alloy, Sci. Technol. Weld. Join. 11 (2006), 583-585 https://doi.org/10.1179/174329306X120886

7. A. Moradian, J. Mostaghimi, Measurement of Surface Tension, Viscosity, and Density at High Temperatures by Free-Fall Drop Oscillation, Metall. Mater. Trans. B. 39 (2008), 280-290 https://doi.org/10.1007/s11663-007-9120-8
8. T. Mukongo, P.C. Pistorius, Viscosity effect of titanium pickup by mould fluxes for stainless steel, Ironmak. Steelmak, 31 (2004), 135 https://doi.org/10.1179/030192304225011115

9. H. Kobatake, J. Brillo, Density and viscosity of ternary Cr-Fe-Ni liquid alloys, J. Mater. Sci., 48 (2013), 6818- 6824 https://doi.org/10.1007/s10853-013-7487-2

10. C. Limmaneevichitr, S. Kou, Experiments to simulate effect of Marangoni convection on weld pool shape, Weld. J, 79 (2000), 231s-237s

11. M.R.U. Ahsan, M. Cheepu, R. Ashiri, T.-H. Kim, C. Jeong, Y.-D. Park, Mechanisms of weld pool flow and slag formation location in cold metal transfer (CMT) gas metal arc welding (GMAW), Weld. World, 61 (2017) https://doi.org/10.1007/s40194-017-0489-y

12. C. Heiple, J. Roper, Effect of selenium on GTAW fusion zone geometry, Weld. J. (1981), 143-145 http:// files.aws.org/wj/supplement/WJ_1981_08_s143.pdf

13. Ji-Sun Kim, Ill-Soo Kim, Chang-Eun Park, Hyun-Ho $\mathrm{Na}$, Ji-Hye Lee and Seong-Myeong Jung, An Experimental Study on Root-pass Welding of Open Gap by GMA Welding Process in Pipeline, Journal of KWJS, 29-3 (2011), 320-325

14. Hyunbyung Chae, Cheolhee Kim, Jeong-Han Kim, Sehun Rhee, Improvement of Gap Bridging Ability in $\mathrm{CO}_{2}$ Laser-GMA Hybrid Welding, Journal of KWJS, 24-5 (2006), 397-404

15. C.R. Heiple, J.R. Roper, Mechanism for Minor Element Effect on \{GTA\} Fusion Zone Geometry, Weld. J. 61 (1982), 97s-102s

16. C. Heiple, J. Roper, R. Stagner, R. Aden, Surface active element effects on the shape of GTA, laser and electron beam welds, Weld. J, (1983), 72-77 http:// ww.aws.org/wj/supplement/WJ_1983_03_s72.pdf

17. R.U. Ahsan, Y.R. Kim, C.H. Kim, J.W. Kim, R. Ashiri, Y.D. Park, Porosity formation mechanisms in cold metal transfer (CMT) gas metal arc welding (GMAW) of zinc coated steels, Sci. Technol. Weld. Join. 21(2015), 1-7 https://doi.org/10.1179/1362171815Y.0000000084 